\title{
Penerapan Metode Continuous Wavelet Transform pada Data Self-Potential Studi pada Tanggul Lapindo Sidoarjo
}

\author{
Rayhan Syauqiya Haf, Sungkono, Bagus Jaya Santosa \\ Departemen Fisika, Fakultas Matematika dan Ilmu Pengetahuan Alam, Institut Teknologi Sepuluh \\ Nopember (ITS) \\ e-mail:bjs@physics.its.ac.id
}

\begin{abstract}
Abstrak-Peristiwa semburan panas lumpur Sidoarjo yang terletak di Kecamatan Porong, Kabupaten Sidoarjo telah memasuki usia 11 tahun. Beragam peristiwa secara fisik telah terjadi seperti rusaknya tanggul yang terjadi akibat adanya saturasi air melalui retakan atau pori-pori tanggul. Berbagai upaya telah dilakukan untuk mengidentifikasi zona rembesan tanggul. Salah satunya dengan menerapkan metode Continuous Wavelet Transform (CWT) pada data Self-Potential (SP). Data yang diperoleh kemudian diolah dengan tujuan untuk mengetahui aplikasi metode CWT pada analisis data SP serta menentukan posisi dan kedalaman anomali. Dari hasil analisis data SP diketahui bahwa metode CWT dapat mengidentifikasi posisi dan kedalaman anomali tanggul Lumpur Sidoarjo serta didapatkan beberapa anomali yang dapat menyebabkan rembesan. Pada Lintasan 1 terdapat 2 anomali, Lintasan 2 terdapat 2 anomali, Lintasan 3 terdapat 3 anomali dan Lintasan 5 terdapat 1 anomali.
\end{abstract}

Kata Kunci-Anomali, Continuous Wavelet Transform, Lumpur Lapindo, Poisson Kernel Family, Self-Potential.

\section{PENDAHULUAN}

$\mathrm{S}_{\mathrm{b}}^{\mathrm{B}}$ EMBURAN Lumpur Panas Sidoarjo, Jawa Timur, sudah berlangsung lebih dari sebelas tahun sejak pertama kali terjadi pada 29 Mei 2006. Volume semburan lumpur terus mengalami peningkatan selama beberapa tahun setelah semburan pertama terjadi. Titik semburan lumpur berlokasi di sekitar $200 \mathrm{~m}$ sebelah barat daya sumur eksplorasi migas Banjarpanji 1. Sejak semburan pertama, laju aliran lumpur meningkat dari $5000 \mathrm{~m}^{3} / \mathrm{d}$ menjadi $120.000 \mathrm{~m}^{3} / \mathrm{d}$ selama sebelas minggu pertama (periode 14 Agustus 2006 sampai 10 September 2006). Kemudian laju aliran lumpur meningkat hampir mencapai $180.000 \mathrm{~m}^{3} / \mathrm{d}$ pada bulan Desember 2006 . Pada bulan Februari 2007, suhu aliran lumpur yang terukur pada jarak 20 meter dari kawah LUSI menunjukkan setinggi $97^{\circ} \mathrm{C}$ sedangkan suhu kawah lumpur tidak dapat diukur secara langsung, namun kemungkinan mencapai $100^{\circ} \mathrm{C}$. Endapannya berupa lumpur dan air dengan perbandingan $70 \%$ air dan $30 \%$ material padat dan telah merendam areal seluas 740 ha. Untuk menanggulangi persebaran lumpur yang semakin luas maka dibangunlah sebuah tanggul [1].

Tanggul LUSI merupakan tanggul buatan dengan komposisi alami yang dipadatkan (earth fill). Tanggul ini dibangun untuk Gambar 1. Lokasi semburan lumpur panas Sidoarjo (Sudarsono dan Sujarwo, 2008)

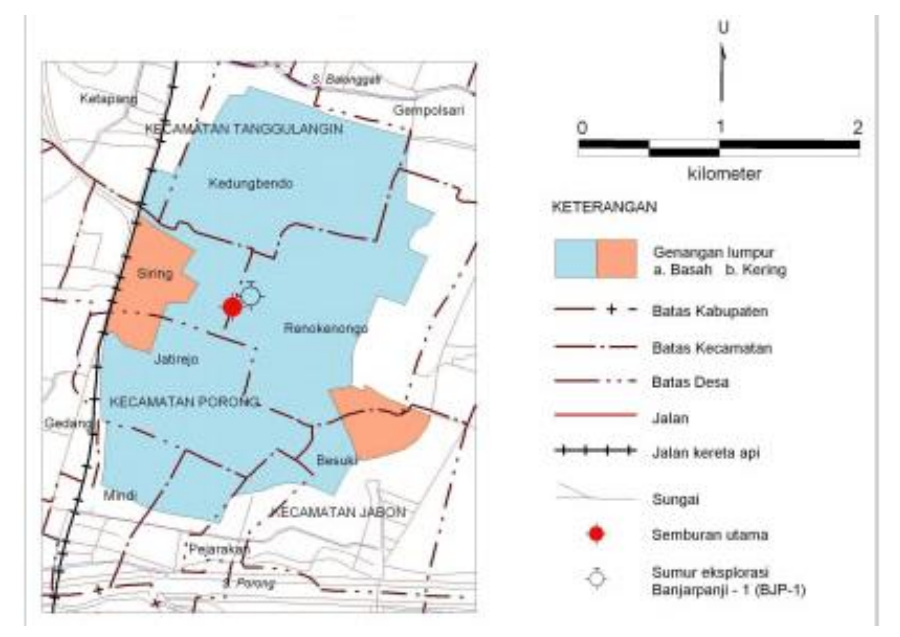

mengurangi dampak yang ditimbulkan oleh erupsi lumpur. Tanggul LUSI sangat rentan terhadap kegagalan-kegagalan yang dapat menyebabkan collapse.

Menurut [2], terdapat tiga hal yang menyebabkan ketidakstabilan pada tanggul LUSI antara lain, deformasi secara vertical dan horizontal, erupsi fluida dalam jumlah yang cukup besar dan likuifaksi pada tanggul seperti yang ditunjukkan pada Gambar 2. Deformasi merupakan perubahan bentuk atau ukuran dari suatu objek baik secara vertikal maupun horizontal. Deformasi pada tanggul dapat menyebabkan retakan pada tanggul akibat dari pergerakan tanggul secara terus menerus. Lumpur yang dikeluarkan dalam jumlah yang besar mengakibatkan terjadinya limpasan (overtopping) sehingga terjadi rembesan fluida pada tanggul (seepage). Fluida tersebut akan berusaha menembus lapisan tanah sehingga terjadi penurunan tanah atau pasir (sand boiling), pasir yang lepas akibat saturasi fluida tersebut dinamakan dengan pasir hisap (quick sand). Penurunan tanah (sand boiling) dan quick sand mengakibatkan suatu getaran gempa yang menjalar pada tanggul sehingga terjadi proses likuifaksi atau berkurangnya kekuatan dankekakuan tanggul tersebut. Selain itu akibat dari erupsi fluida tersebut dapat mengakibatkan longsoran (sliding) [2].

Tanggul LUSI sangat rentan terhadap kegagalan sehingga dapat menimbulkan keruntuhan (collapse). Apabila tanggul mengalami keruntuhan maka akan berdampak buruk bagi 
lingkungan sekitar. Oleh karena itu perlu dilakukan monitoring secara berkala terkait kestabilan tanggul tersebut. Metode Geofisika dapat digunakan untuk mengetahui tingkat Gambar 2. Jenis Kegagalan tanggul

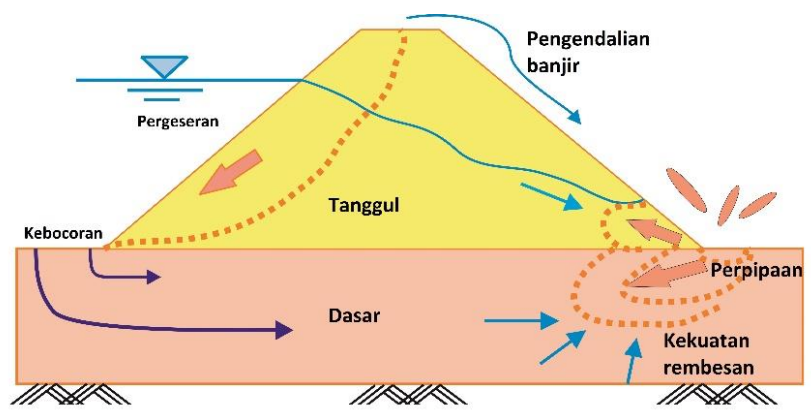

kestabilan tanggul. Salah satunya dengan menggunakan metode Self-Potential. Metode ini dipilih karena merupakan metode non destructive dan hasilnya akurat.

Metode potensial diri (Self-Potential) merupakan salah satu metode geofisika pasif yang prinsip kerjanya dengan mengukur tegangan statis alam (static natural voltage) yang berada pada titik-titik dipermukaan tanah. Metode potensial diri (Self-Potential) dikatakan metode yang pasif karena untuk mendapatkan informasi bawah permukaan tanah dapat dilakukan melalui pengukuran tanpa perlu menginjeksi arus listrik. Potensial listrik di permukaan tanah diukur dengan menggunakan voltmeter dan kontak antara voltmeter dengan tanah menggunakan suatu elektroda non polar (non-polarizing electrodes). Hasil akhir dari survei potensial diri adalah data berupa nilai potensial terukur dengan jarak spasi tertentu yang kemudian dibuat grafik antara offset dengan nilai potensial terukur dan peta kontur ekuipotensial [3].

Metode Continuous Wavelet Transform (CWT) merupakan salah satu perkembangan dari metode Fourier Transform dimana metode tersebut dapat mengidentifikasi frekuensi dan posisi yang menghasilkan frekuensi tersebut secara bersamaan sehingga metode ini dapat digunakan pada sinyal yang nonstasioner. Metode Continuous Wavelet Transorm menggunakan persamaan turunan Poisson Kernel Family. Dimana memiliki 10 jenis wavelet, 5 turunan secara Horisontal dan 5 turunan secara Vertikal.

$$
H_{n}(u)=(2 \pi u)^{n} \exp (-2 \pi|u|)
$$

dengan u menotasikan bilangan gelombang dari variabel spasial, x mempresentasikan domain frekuensi da $\mathrm{n}$ menjadi urutan turunan, seperti $\mathrm{n} \in \mathrm{N}$. Demikian pula, jika menggunakan transformasi Hilbert dari wavelet horisontal, persamaan umum turunan vertikan poisson kernel family, $\mathrm{V}_{\mathrm{n}}(\mathrm{u})$, adalah

$$
V_{n}(u)=-2 \pi|u|(2 \pi i u)^{(n-1)} \exp (-2 \pi|u|)
$$

dengan u merupakan transformasi Fourier dari variabel spasial, $\mathrm{x}$ pada frekuensi dominan dan $\mathrm{n}$ sebagai perintah turunan. Gambar 3. Ekstrema koefisien wavelet phase (atas) dan koefisien wavelet modulus (tengah untuk data Self-Potential (bawah)

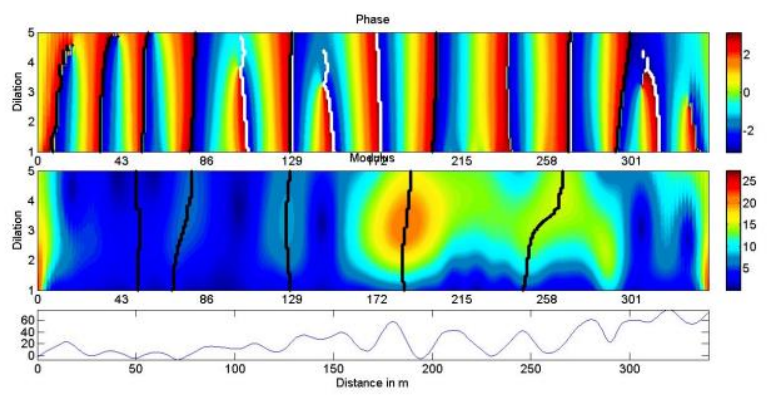

Metode ini hanya dapat digunakan pada bidang potensial. Posisi dan kedalaman sumber anomali dapat diindentifikasi melalui perpotongan garis ekstrema (singularitas). Untuk melakukannya secara akurat, dalam menganalisis wavelet harus dilakukan dengan urutan dervatif, hal tersebut memiliki hasil yang lebih baik daripada menggunakan distribusi sumber homogen [4].

\section{METODOLOGI PENELITIAN}

Pengolahan data untuk mengetahui posisi dan kedalaman rembesan Lumpur Lapindo dilakukan dengan menggunakan metode Continuous Wavelet Transform (CWT). Data yang digunakan merupakan data Self-Potential dengan cara akuisisi menggunakan metode Fix Base dari 5 lintasan tanggul pada titik P79-82, P78-79, P76-77, P75A dan Ptabendo. Data yang didapat merupakan data beda potensial dengan jarak antar titik pengukuran sejauh 5 meter.

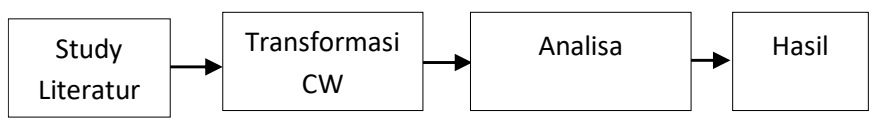

Gambar 4. Diagram alir penelitian

Identifikasi tersebut dilakukan dengan menggunakan MATLAB 2009a dengan menggunakan Source Code. Source Code metode CWT dikembangkan oleh [4]. Source Code tersebut terbagi menjadi dua macam; yang pertama yaitu MWTmatanalyse.m dan MWTmatdepth.m. Pada Source Code MWTmatanalyse.m, didalamnya meliputi persamaan wavelet, transformasi kontinyu dan filter extrema. Sedangkan pada Source Code MWTmatdepth.m, didalamnya meliputi regresi linear, perhitungan kedalaman sumber dan perhitungan koefisien struktur.

\section{ANALISIS DATA DAN PEMBAHASAN}

A. Pengolahan Data dengan Menggunakan Continuous Wavelet Transform (CWT)

Continuous Wavelet Transform (CWT) merupakan salah satu metode transformasi yang dapat digunakan untuk menentukan kedalaman, struktural order dan informasi phase yang berkaitan dengan sumber yang menghasilkan data SP. Analisis CWT didasarkan pada transformasi wavelet kontinyu yang diterapkan pada bidang potensial (Self-Potential, Graviti dan Magnetik) menggunakan wavelet Poisson Kernel Family. 


\section{Continuous Wavelet Transform (CWT) untuk Analisis Posisi}

Dalam menganalisis posisi sumber anomali pada penelitian ini menggunakan batas rentang dilatasi minimum sebesar 1 dan batas rentang dilatasi maksimum sebesar 5 serta angka dilatasi sebesar 500. Penggunaan rentang dilatasi minimal sebesar 1dan maksimal sebesar 5 sebab jumlah titik yang digunakan pada penelitian ini tidak lebih atau sama dengan 576 titik. Dalam penelitian ini menggunakan 6 jenis wavelet yaitu 3 turunan secara horisontal dan 3 turunan secara vertikal. Hal ini digunakan untuk mengetahui nilai ketidakpastian sumber anomali.

Selain itu, untuk menganalisis posisi dengan menggunakan metode CWT, kontrol pertama yang perlu dilakukan dan terpenting dengan meninjau teorema Nyquist-Shanon, yang mana metode CWT didasarkan pada struktur wavelet yang dianalisis. Resolusi frekuensi yang buruk dari wavelet akan menghasilkan matriks koefisien wavelet yang kurang akurat, sehingga perhitungan kedalaman juga kurang akurat. Sebagaimana yang telah ditentukan oleh teorema NyquistShannon, sampling dari frekuensi wavelet yang dianalisis harus sama dengan atau lebih dari dua kali yang diperlukan dalam menentukan wavelet pada frekuensi tinggi. Oleh karena itu, Source Code CWT dikembangkan sedemikian rupa sehingga analisis wavelet pada dilatasi minimum berada pada frekunsi tinggi.

Untuk menghindari kesalahan menganalisis posisi sumber anomali yang diakibatkan karena rentang dilatasi yang terlalu kecil, algoritma metode CWT tersebut secara otomatis menolak sinyal input yang tidak dapat mendukung dilatasi maksimum. Dalam proses analisis posisi sumber anomali, tidak ada batasan tertentu untuk jumlah titik maksimal. Namun semakin banyak jumlah data semakin besar juga data matriks yang dihasilkan dan waktu analisis CWT juga semakin lama.

Gambar 4(a) merupakan koefisien real sedangkan gambar (b) merupakan koefisien imajiner. Gambar 5 (a) merupakan koefisien phasesedangkan gambar (b) merupakan koefisien modulus. Pada kedua gambar tersebut terdapat garis-garis berwarna hitam maupun putih.Garis tersebut merupakan ekstrema. Ekstrema adalah garis yang terbuat dari koefisien wavelet yang memiliki nilai optimum lokal.

Beberapa ekstrema yang ditunjukkan pada Gambar 4 dan Gambar 5 menunjukkan singularitas yang terkait dengan sumber sinyal dan yang lainnya menunjukkan adanya noise. Dalam analisis sinyal, ekstrema yang berupa noise frekuensi

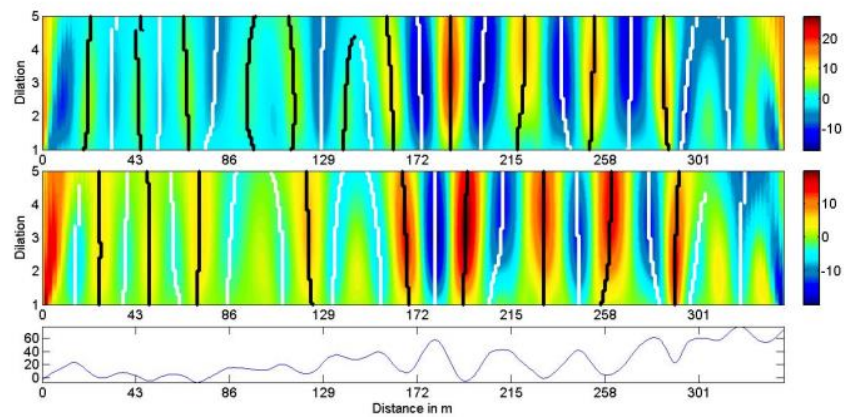

Gambar 5. Ekstrema koefisien wavelet real (atas) dan koefisien wavelet imajiner (tengah untuk data Self-Potential (bawah) tinggi yang terdeteksi oleh wavelet pada frekuensi tinggi atau dilatasi rendah. Jika pada sinyal yang dianalisis tidak mengandung atau terdapat sedikit noise, panjang minimal ekstrema yang digunakan harus relatif kecil. Sebaliknya, jika terdapat banyak noise pada sinyal, maka panjang ekstrema harus ditetapkan cukup besar. Hal ini untuk menghilangkan ekstraksi benda-benda bawah permukaan lain yang ikut terekam. Ekstrema ini juga berfungsi untuk proses filtering dengan menghilangkan ekstrema yang mencerminkan noise tanpa kehilangan informasi ekstrema sebenarnya.

Bilangan matriks kompleks (terdiri dari bilangan real dan imajiner) hasil CWT dalam ruang 2D (jarak, pelebaran, dsb) yang berisi tentang informasi yang berkaitan dengan sumber sinyal yang dianalisis. Jadi, dari matriks koefisien wavelet, sumber sinyal yang diteliti dapat ditemukan dengan menggunakan koefisien real dan imajiner. Sedangkan koefisien phase (Gambar 5) dapat digunakan untuk menghitung orientasi kemiringan sumber sinyal. Matriks modulus menunjukkan satu ekstrema yang mewakili sumber anomali sumbu jarak. Hal tersebut memungkinkan untuk menghitung orientasi kemiringan sumber anomali.

\section{Continuous Wavelet Transform (CWT) untuk Analisis \\ Kedalaman}

Untuk analisis kedalaman sumber anomali menggunakan metode CWT dapat ditentukan melalui 3 bagian, yaitu:perhitungan kedalaman, regresi linier, dan perhitungan koefisien struktur. Analisis kedalaman sumber anomali dilakukan dengan menggunakan jenis-jenis wavelet yang berbeda. Untuk mengidentifikasi kedalaman pada jenis wavelet H1 menggunakan koefisien wavelet imajiner, pada jenis wavelet $\mathrm{H} 2$ menggunakan koefisien wavelet real, dan pada jenis wavelet $\mathrm{H} 3$ menggunakan koefisien wavelet imaginary. Sedangkan untuk wavelet turunan secara vertikal berkebalikan dengan turunan secara horisontal atau dapat dilihat pada Tabel 1 .

Untuk membuat perhitungan kedalaman anomali dan membantu memilih ekstrema yang mengandung anomali, nilai amplitud dihitung pada setiap ekstrema. Nilai amplitud adalah

Tabel 1.

Jenis-jenis wavelet pada Poisson Kernel Family

\begin{tabular}{lcccc}
\hline Turunan & Urutan & Nama & Imajiner & Real \\
\hline Horisontal & 1 & H1 & Ya & Tidak \\
Horisontal & 2 & H2 & Tidak & Ya \\
Horisontal & 3 & H3 & Ya & Tidak \\
Horisontal & 4 & H4 & Tidak & Ya \\
Horisontal & 5 & H5 & Ya & Tidak \\
Vertikal & 1 & V1 & Tidak & Ya \\
Vertikal & 2 & V2 & Ya & Tidak \\
Vertikal & 3 & V3 & Tidak & Ya \\
Vertikal & 4 & V4 & Ya & Tidak \\
Vertikal & 5 & V5 & Tidak & Ya \\
\hline \hline
\end{tabular}

rata-rata nilai absolut koefisien wavelet yang menentukan ekstrema. Untuk sumber yang sama, jumlah ekstrema yang terkonvergensi ke arah sumber anomali dapat berkisar antara 2 sampai lebih dari 5 ekstrema. Dengan demikian, kombinasi 
dari ekstrema tersebut dapat dipilih untuk menghitung kedalaman. Namun, ditekankan untuk ekstrema yang memiliki nilai koefisien wavelet tertinggi.

Untuk menentukan kedalaman sumber anomali menggunakan regresi linier pada garis ekstrema. Pada data

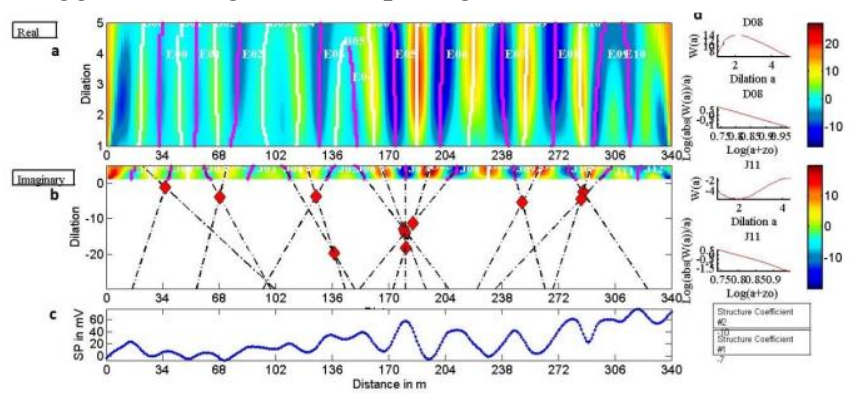

Gambar 6. Ekstrema koefisien wavelet ral (atas) dan singularitas koefisien wavelet imajiner (tengah untuk data Self-Potential (bawah)

tanpa noise atau terdapat sedikit noise, masing-masing memiliki bentuk regresi linier tertentu. Namun, adanya noise pada data yang kompleks menyebabkan garis ekstrema terdistorsi, hal tersebut dapat menghasilkan kesalahan pada perhitungan kedalaman sumber sinyal. Untuk membatasi noise, metode CWT memiliki dua pilihan yang dapat digunakan yaitu regresi linier otomatis atau regresi linier grafis, yaang mana keduanya memiliki kelebihan dan kelemahan masing-masing.

Pada regresi linier secara otomatis, menggunakan bobot pada fungsi objektif dengan mempertimbangkan nilai absolut masing-masing koefisien wavelet yang menghasilkan ekstrema. Semakin tinggi nilai absolut koefisien wavelet, akan semakin baik juga singularitas. Hal ini menunjukkan bahwa bobot pada fungsi objektif dapat mengkarakterisasi sumber anomali dengan lebih baik. Jika koefisien wavelet dan noise memiliki nilai frekuensi yang mirip, regresi linier otomatis tidak bisa memberikan informasi kedalaman sumber anomali dengan tepat. Sedangkan, jika memilih regresi linier grafis, hanya dapat memilih setidaknya tiga ekstrema yang terdapat noise. Hal tersebut dapat menghindari bagian ekstrema yang terdapat noise. Dikarenakan hanya dapat memilih tiga titik, maka dalam menggunakan regresi linier grafis harus berhati-hati agar tidak terjadi kesalahan. Untuk menghindari kesalahan dalam memilih 3 titik yang mewakili anomalu, maka pada penelitian ini menggunakan regresi linier secara otomatis.

Gambar 6 (b) menunjukkan titik perpotongan antara garis ekstrema bernilai positif dan negatif. Titik perpotongan tersebut mengindikasikan posisi dan kedalaman dari anomali dari data. Namun agar hasil posisi dan kedalaman anomali lebih akurat, penentuan posisi dan kedalaman anomali dengan memadukan minimal 4 jenis wavelet yang mengindikasikan posisi serupa.

\section{B. Analisis dan Interpretasi Data Self-Potential pada Setiap Lintasan Pengukuran}

Untuk menenilai stabilitas tanggul diperlukan suatu metode yang dapat memetakan zona rembesan pada tanggul tersebut. Salah satu metode yang dapat menyelidiki rembesan pada tanggul adalah Self-Potential. Pengukuran tersebut didasarkan pada pengukuran potential listrik yang disebabkan oleh air yang bergerak dalam medium berpori [5].
Hasil analisis yang telah dilakukan dengan menggunakan metode CWT. Selanjutnya dilakukan pembuatan grafik perbandingan beda potensial dan posisi serta kedalaman dan posisi anomali.
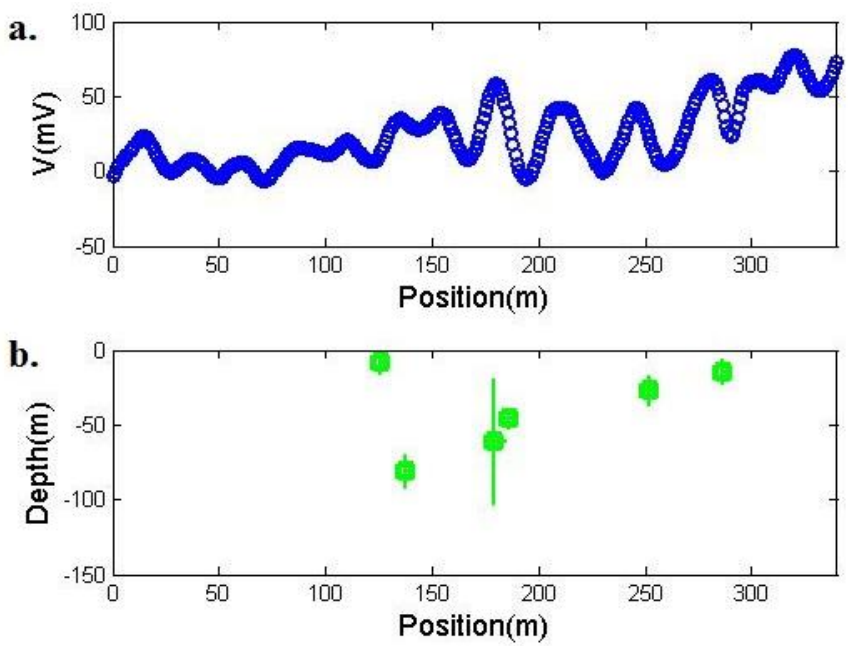

Gambar 7. Perbandingan beda potensial (V) dengan kedalaman anomali pada Lintasan 1 Tanggul LUSI

\section{Lintasan 1 (P79-82)}

Gambar 7. menunjukkan perbandingan beda potensial dengan posisi dan kedalaman anomali pada Lintasan 1. Gambar ini menunjukkan bahwa pada daerah tersebut terdapat 2 anomali yang dapat menyebabkan rembesan tanggul (Gambar 7). Anomali pertama terletak pada posisi $125,72 \pm 1,14$ dengan kedalaman $-8,72 \pm 7,61$. Anomali kedua, terletak pada posisi $286,28 \pm 0,99$ dengan kedalaman $14,51 \pm 8,28$. Sebab tanggul pada umumnya hanya memiliki ketebalan $\pm 15 \mathrm{~m}$ sedangkan anomali dengan kedalaman lebih dari $15 \mathrm{~m}$ kemungkinan retakan yang diakibatkan oleh penurunan tanah yang berlebihan.

\section{Lintasan 2 (P78-79)}

Gambar 8. menunjukkan perbandingan beda potensial dengan kedalaman anomali pada Lintasan 2. Gambar ini menunjukkan bahwa pada tanggul tersebut terdapat 2 anomali
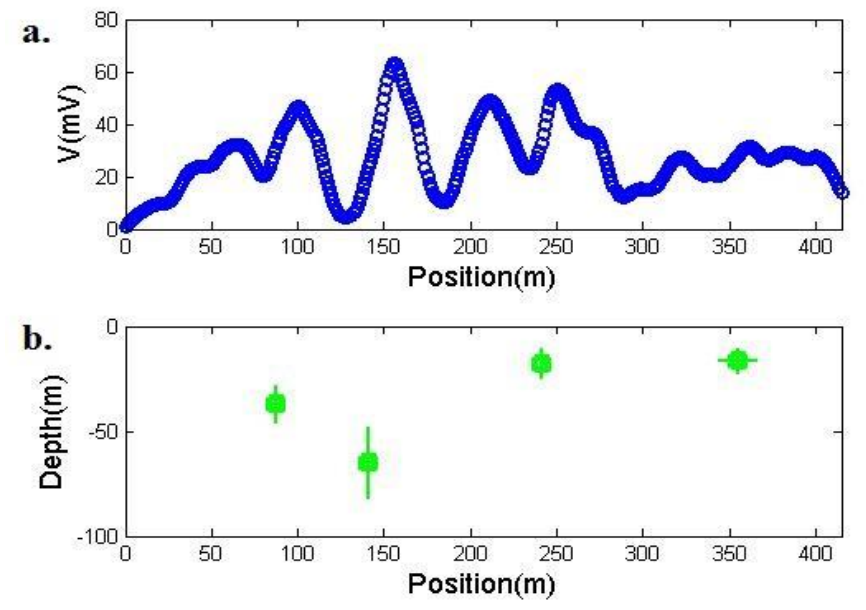

Gambar 8. Perbandingan beda potensial (V) dengan kedalaman anomali pada Lintasan 2 Tanggul LUSI 

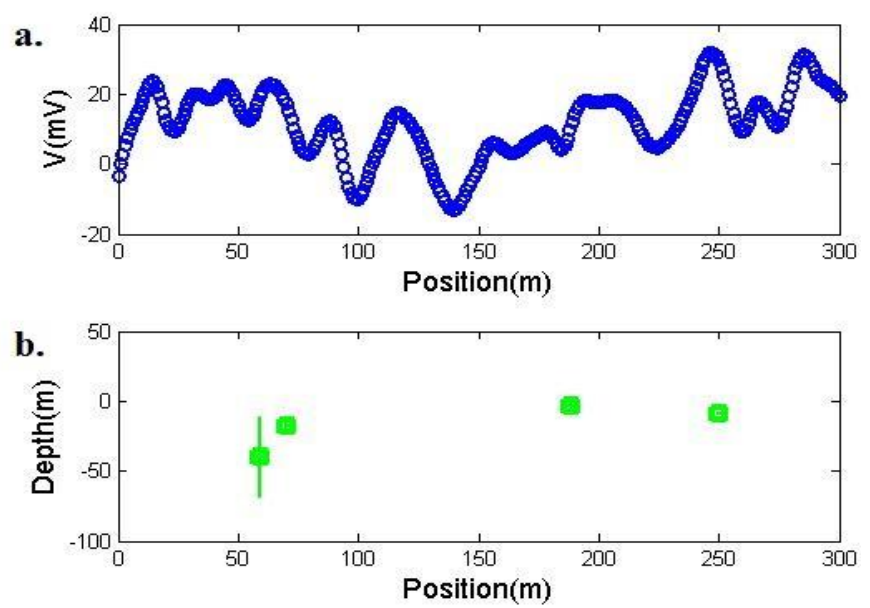

Gambar y. rerbanaıngan beaa porensıa ( $\mathrm{v}$ ) dengan kedaıman anomaı pada Lintasan 3 Tanggul LUSI

yang dapat menyebabkan rembesan tanggul (Gambar 8b). Anomali pertama terletak pada posisi $241,87 \pm 0,72$ dengan kedalaman $-17,85 \pm 6,84$. Anomali kedua terletak pada posisi $354,81 \pm 11,02$ dengan kedalaman $-16,84 \pm 5,90$. Anomali dengan kedalaman lebih dari $15 \mathrm{~m}$ kemungkinan retakan yang diakibatkan oleh penurunan tanah yang berlebihan.

\section{Lintasan 3 (P76-77)}

Gambar 9 menunjukkan perbandingan beda potensial dengan kedalaman dan posisi anomali Lintasan 3. Gambar ini menunjukkan bahwa pada daerah tersebut terdapat 3 anomali yang menyebabkan rembesan tanggul (Gambar 4.9b). Anomali pertama terletak pada posisi 249,66 $\pm 0,67$ dengan kedalaman $8,60 \pm 0,68$. Anomali kedua terletak pada posisi $188,09 \pm 1,42$ dengan kedalaman $-3,25 \pm 3,39$. Anomali ketiga terletak pada posisi $70,23 \pm 0,46$ dengan kedalaman $-18,10 \pm 2,42$. Sebab tanggul umumnya memiliki ketebalan $\pm 15 \mathrm{~m}$ sedangkan anomali dengan kedalaman lebih dari $15 \mathrm{~m}$ kemungkinan retakan yang disebabkan oleh penurunan tanah yang berlebihan.

\section{Lintasan $4(P 75 A)$}
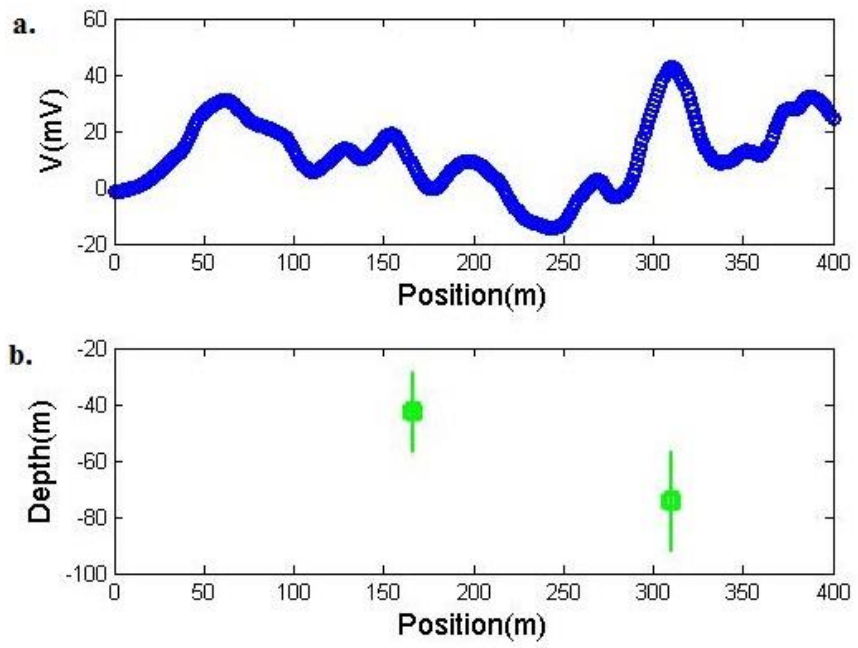

Gambar 10. Perbandingan beda potensial (V) dengan kedalaman anomali pada Lintasan 2 Tanggul LUSI

Lintasan 4 merupakan tanggul dengan koordinat P75A. Gambar 10 menunjukkan perbandingan beda potensial dengan kedalaman anomali pada Lintasan 4 tanggul Lumpur Sidoarjo. Gambar 10 menunjukkan perbandingan beda potensial dengan posisi dan kedalaman anomali. Gambar ini menunjukkan
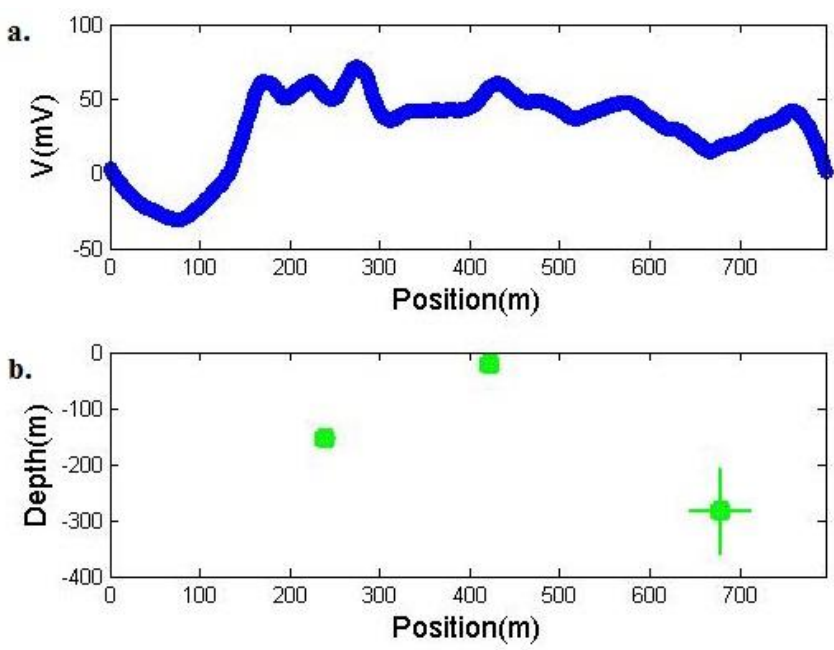

Gambar 11. Merbandingan beda potensial ( $\mathrm{V}$ ) dengan kedalaman anomali pada Lintasan 5 Tanggul LUSI

bahwa pada tanggul tersebut tidak terdapat rembesan tanggul dikarenakan anomali yang teridentifikasi memiliki kedalaman yang lebih dari $15 \mathrm{~m}$ yang mengindikasikan kemungkinan adanya retakan yang diakibatkan oleh penurunan tanah yang berlebihan.

\section{Lintasan 5 (Ptabendo)}

Gambar 11 menunjukkan perbandingan beda potensial dengan kedalaman anomali pada Lintasan 5 tanggul Lumpur Sidoarjo. Gambar ini menunjukkan bahwa pada daerah tersebut terdapat 1 anomali yang menyebabkan rembesan tanggul (Gambar 11b). Anomali tersebut terletak pada posisi $422,32 \pm 8,41$ dengan kedalaman $-22,5 \pm 6,74$. Sebab tanggul umumnya memiliki ketebalan $\pm 15 \mathrm{~m}$ sedangkan anomali dengan kedalaman lebih dari $15 \mathrm{~m}$ kemungkinan retakan yang disebabkan oleh penurunan tanah yang berlebihan.

\section{KESIMPULAN/RINGKASAN}

Berdasarkan dari hasil pengolahan dan interpretasi data Self-Potential pada tanggul Lumpur Sidoarjo, maka dapat diambil kesimpulan sebagai berikut:

1. Metode Continuous Wavelet Transform (CWT) dapat mengidentifikasi posisi dan kedalaman anomali tanggul Lumpur Sidoarjo dengan menggunakan data Self-Potential.

2. Dari hasil interpretasi data Self-Potential didapatkan kemungkinan posisi dan kedalaman lokasi rembesan pada tanggul Lumpur Sidoarjo terdapat pada Lintasan 1, Lintasan 2, Lintasan 3 dan Lintasan 5

\section{DAFTAR PUSTAKA}

[1]

[2]
M. A. S. H. A. G. A. G. P. S. et. Al., "Triggering and dynamic evolution of the LUSI mud volcano, Indonesia," 2007.

Sungkono, A. Husein, H. Prasetyo, A. S. Bahri, F. A. Monteiro Santos, and B. J. Santosa, "The VLF-EM imaging of potential 
collapse on the LUSI embankment," J. Appl. Geophys., vol. 109, no. 109, pp. 218-232, Oct. 2014.

[3] U. W. Supeno, Nugroho T. Agung, "Survei Potensi Sumber Daya Mineral di Kecamatan Silo Kabupaten Jember dengan menggunakan Metode Potensial Diri," J. Fis. dan Apl., vol. 5, no. $1,2009$.

[4] G. Mauri, G. Williams-Jones, and G. Saracco, "MWTmatapplication of multiscale wavelet tomography on potential fields," Comput. Geosci., vol. 37, pp. 1825-1835, 2011.

[5] A. A. OGILVY, M. A. AYED, and V. A. BOGOSLOVSKY, "GEOPHYSICAL STUDIES OF WATER LEAKAGES FROM RESERVOIRS*," Geophys. Prospect., vol. 17, no. 1, pp. 36-62, Mar. 1969. 